\title{
PENINGKATAN PENDIDIKAN KESIAPSIAGAAN BENCANA SEKOLAH DASAR BENGKULU MELALUI PEMBELAJARAN TEMATIK TERPADU DAN MEDIA ICT
}

\section{DISASTER PREPAREDNESS EDUCATION ENHANCEMENT FOR BENGKULU PRIMARY THROUGH INTEGRATED THEMED LEARNING AND MEDIA ICT}

\author{
Oleh: \\ Endang Widi Winarni ${ }^{1}$, Feri Noperman, Endina Putri Purwandari ${ }^{2}$ \\ ${ }^{l}$ PGSD FKIP Universitas Bengkulu \\ ${ }^{2}$ Teknik Informatika Fakultas Teknik Universitas Bengkulu \\ endangwidi@unib.ac.id
}

\begin{abstract}
The aims of this dedication activity were: (1) prepared human resources, infrastructures, and learning model about disaster preparedness; (2) disseminated learning model of disaster preparedness through integrative thematic learning; (3) disseminated learning model of disaster preparedness through ICT media. This activity used observational and modelling method with four phases, i.e., attentional phase, retension phase, reproduction phase, and motivation phase. The result of this activity indicated that all teacher (100\%) have true perception and comprehension about disaster risk reduction program. Besides, this activity produced of learning plan and online learning resource about disaster risk reduction program. The online learning resource can be accessed by www.wartabencana.com.
\end{abstract}

Keywords: learning model of disaster preparedness, the reduction of disaster risk program

\section{PENDAHULUAN}

Gempa bumi merupakan salah satu peristiwa alam yang sulit dideteksi kapan akan terjadinya. Gempa bumi juga menjadi salah satu bencana alam yang dampak kerusakannya begitu besar bagi kehidupan manusia. Wilayah terjadinya gempa bumi adalah di dekat titik pertemuan antar lempeng bumi, misalnya di pesisir barat pulau sumatera. Propinsi Bengkulu merupakan salah satu propinsi di pesisir barat pulau sumatera yang sering mengalami gempa bumi. Gempa bumi terbesar yang pernah terjadi adalah gempa pada tanggal 4 Juni tahun 2000 berkekuatan 7,3 skala richter yang mengakibatkan:

1. Korban jiwa: 88 meninggal dunia, 959 luka berat dan 2207 luka ringan,

2. Kerusakan gedung Sekolah dan Madrasah sebanyak 387 unit tergolong rusak berat dan 156 tergolong rusak ringan,

3. Kerusakan bangunan rumah penduduk yaitu rumah roboh sebanyak 1.733 unit, rusak berat 16.588 unit dan rusak ringan sebanyak 28.073 unit (Kompas, 12 Januari 2005).

Kemudian pada gempa bumi tanggal 12 September 2007 berkekuatan 7,9 skala 
Richter mengakibatkan: (1) kerusakan rumah tercatat 4.759 unit rusak total, 7.444 rumah rusak berat, dan 5.594 rumah rusak ringan; (2) gedung sekolah yang rusak sebanyak 245 unit rusak total, 302 sekolah rusak berat, dan 234 sekolah rusak ringan, dengan jumlah kerusakan terberat di Kabupaten Mukomuko (Kompas, 15 September 2007).

Siswa sekolah dasar di provinsi Bengkulu rentan terkena dampak gempa bumi. Apalagi banyak Sekolah Dasar yang terletak dekat pantai, misalnya Sekolah Dasar Negeri 11 Kota Bengkulu. SD ini terletak sangat dekat dengan pantai pesisir Bengkulu dan beralamat di J1. Kolonel Barlian Kelurahan Malabero Kecamatan Teluk Segara yang berjarak sekitar 4 (empat) km dari kampus Universitas Bengkulu. Sekolah ini pada saat terjadi gempa bumi tahun 2000, mengalami kerusakan fasilitas gedung sekolah yang sangat parah bahkan akhirnya keseluruhan gedung dihancurkan kemudian dengan bantuan dari Jerman dibangunlah gedung baru dengan konstruksi tahan terhadap gempa bumi serta tangga untuk jalur evakuasi jika terjadi gempa.

Rencana tindak lanjut dari tersedianya gedung dan fasilitas tersebut, SDN 11 telah merumuskan Visi yaitu: Menghasilkan lulusan yang berprestasi, budi pekerti luhur dalam membentuk Insan Sekolah yang Taqwa kepada Tuhan Yang Maha Esa dan Tanggap terhadap Bencana”. Misi SDN 11 Kota Bengkulu adalah: (1) Melaksanakan proses belajar mengajar dan bimbingan secara efektif dan efisien kepada siswa sehingga dapat berkembang secara optimal sesuai dengan potensi yang dimiliki; (2) mengupayakan pembinaan mental, akhlak, dan budi pekerti; (3) melibatkan komite sekolah untuk mencapai hasil yang optimal; (4) mengupayakan pembinaan pembelajaran dari instansi terkait; (5) meningkatkan Kondisi sekolah siap siaga terhadap bencana.

Berdasarkan kondisi SD tersebut maka dapat dirumuskan permasalahan dalam kegiatan ini, yaitu "Apakah kapasitas SDM, sarana prasarana sekolah, dan model pembelajaran kesiapsiagaan bencana (baik secara tematik maupun terintegrasi ke dalam mata pelajaran) dapat meningkatkan kepedulian dan sikap siaga bencana bagi siswa?”

Berdasarkan rumusan masalah tersebut di atas, maka tujuan kegiatan ini, adalah:

1. Mempersiapkan kapasitas SDM, sarana prasarana sekolah, dan model pembelajaran kesiapsiagaan bencana (baik secara tematik maupun terintegrasi ke dalam mata pelajaran) untuk meningkatkan kepedulian dan SSB bagi siswa SD.

2. Mensosialisakan model pembelajaran kesiapsiagaan bencana melalui pembelajaran tematik dan terintegrasi ke dalam mata pelajaran sehingga dapat meningkatkan kapasitas SDM (Kepala Sekolah dan guru SD) dalam menyiapkan layanan kesiapsiagaan bencana di sekolah mitra.

3. Mensosialisasikan model pembelajaran kesiapsiagaan bencana melalui pembelajaran tematik dan terintegrasi ke dalam mata pelajaran berbasis ICT sehingga dapat meningkatkan pemahaman dan sikap kepedulian siswa tentang kesiapsiagaan bencana di sekolah mitra. 


\section{METODE PENGABDIAN}

Kegiatan IbM ini dilaksanakan melalui kegiatan observasional dan modelling dengan empat fase, yaitu: fase perhatian (attential phase), fase retensi (retention phase), fase reproduksi (reproduction phase), dan fase motivasi (motivation phase) (Winarni, dkk., 2011). Fase perhatian, dilakukan dengan membentuk Focus Group Discusion (FGD) yang berkaitan dengan:

1. Pemahaman tentang pendidikan kesiapsiagaan bencana,

2. Kapasitas sarana prasarana sekolah untuk menunjang pelaksanaan program PRB,

3. SOP penyelamatan diri saat terjadi bencana gempa bumi di sekolah,

4. Model pembelajaran yang mengintegrasikan pendidikan kesiapsiagaan kedalam pembelajaran tematik, dan

5. Sumber belajar yang disajikan dalam www.wartabencana.com.

Fase retensi, dilakukan simulasi dan penampilan model atau penyajian secara simbolik tentang pelaksanaan pendidikan kesiapsiagaan bencana terintegrasi kedalam tematik oleh tim IbM. Guru mitra mengamati kegiatan pemodelan yang dilakukan oleh tim IbM, hingga guru mitra memiliki kemampuan untuk melaksanakan pembelajaran seperti rangkaian yang dimodelkan oleh tim pelaksana pengabdian kepada masyarakat.

Fase reproduksi, pada fase ini guru SD sebagai mitra telah menunjukkan kemampuan tampil menjadi model baru atau mampu melakukan pengulangan pelaksanaan pendidikan kesiapsiagaan terintegrasi dengan benar dan efektif.

Fase motivasi, fase terakhir dari pelaksanaan kegiatan ini ditandai dengan meningkatnya kemampuan guru sebagai mitra untuk merancang pelaksanaan pendidikan kesiapsiagaan bencana melalui pembelajaran tematik secara berkelanjutan.

Sosialisasi dan implementasi pendidikan kesiapsiagaan bencana melalui pembelajaran tematik berbasis ICT bagi siswa sekolah dasar menjadi sangat penting dan urgen. Hal tersebut menjadi urgen, dikarenakan bencana alam yang melanda suatu daerah selalu menyisakan duka dan derita yang mendalam, menyebabkan trauma keluarga korban terutama anak-anak (Kompas, 14 Januari 2005). Salah satu yang dapat dilakukan mulai sekarang adalah menggagas dan melaksanakan pendidikan kesiapsiagaan bencana (disaster preparedness education) baik melalui kegiatan kurikuler maupun ekstrakurikuler.

\section{HASIL DAN PEMBAHASAN}

\section{Pemahaman Guru SD tentang Program PRB}

Pemahaman guru SD mitra diukur menggunakan instrumen yang mencakup:

1. Pendidikan kesiapsiagaan pra bencana,

2. Saat terjadi bencana,

3. Pasca bencana, dan pengembangan kapasitas sekolah.

Jumlah guru yang mengikuti kegiatan ini berjumlah 8 orang yang berasal dari SDN 
11 dan SDN 69 masing-masing berjumlah empat orang. Berdasarkan data yang diperoleh menunjukkan bahwa guru pada kedua SD mitra sudah memiliki wawasan tentang rumusan visi sekolah yaitu kesiapsiagaan bencana.

Aspek pemahaman guru tentang program PRB yang telah mencapai respons $100 \%$ adalah:

1. Melaksanakan drill penyelamatan diri siswa diintegrasikan ke dalam pembelajaran tematik terpadu,

2. Meningkatkan kesadaran siswa dalam penyelamatan diri ketika terjadi bencana gempa melalui Yel-yel,

3. Meningkatkan pemahaman siswa tentang kesiapsiagaan bencana melalui tugas pembuatan kliping,

4. Merancang RPP tematik terintegrasi PRB. Sedangkan aspek pemahaman guru tentang program PRB yang telah mencapai respons $60 \%$ adalah melaksanakan latihan penyelamatan diri secara incidental dan Memfasilitasi siswa dengan informasi PRB secara on-line (berbasis ICT).

\section{RPP PembelajaranTematik Terpadu Terintegrasi PRB}

Perangkat pembelajaran pendidikan kesiapsiagaan bencana yang disusun oleh guru mitra dengan pendampingan tim pelaksana kegiatan IbM. Penentuan tema disesuaikan dengan standar isi pada Kurikulum 2013. Penyusunan RPP diselaraskan dengan ramburambu penyusunan RPP Kurikulum 2013, dan telah disusun 5 buah RPP mulai kelas 1 sampai kelas 5, yaitu:

\section{Tema Peristiwa Alam (kelas 1)}

2. Tema Keselamatan di rumah dan di perjalanan (kelas 2)

3. Tema Pengalaman yang Mengesankan (kelas 3)

4. Tema Daerah Tempat Tinggalku (kelas 4)

5. Tema Peristiwa dalam Kehidupan (kelas 5).

\section{Penyajian Materi PRB sebagai Sumber Belajar secara On-line}

Penyajian materi PRB sebagai sumber belajar dapat diakses secara online melalui alamat website www.wartabencana.com. Website ini menyajikan materi-materi kesiapsiagaan bencana, langkah- langkah penyelamatan diri pada saat terjadi gempa bumi, produk-produk pembelajaran, materi gempa bumi, hasil kegiatan, foto kegiatan, dan video kegiatan. Menu-menu yang tersedia yaitu (a) bentuk-bentuk gempa bumi, pergerakan tektonik bumi, perubahan rupa bumi, alat pengukur gempa, aturan scala richter, posisi Indonesia dalam Ring of Fire; (2) sejarah gempa bumi menberikan informasi daftar sejarah kejadian-kejadian gempa bumi yang terjadi di Indonesia; (3) istilah- istilah dalam kegempaan; (4) jenis- jenis gempa bumi dan pembagian gempa bumi berdasarkan penyebab, kedalaman, dan gelombang/getaran gempa; (5) animasi tsunami, berbentuk video pembelajaran proses terjadinya tsunami; (6) video pembelajaran gempa bumi; (7) link-link terkait dengan informasi belajar gempa bumi; (8) presentasi siap siaga bencana, dokumen 
presentasi yang dapat digunakan oleh guru untuk pembelajaran siap siaga bencana di kelas; dan (9) 5 buah RPP mulai kelas 1 sampai kelas 5 berdasarkan kurikulum 2013 yang telah terintegrasi dengan materi pengurangan resiko bencana.

Guru di SD mitra sudah memiliki wawasan tentang rumusan visi sekolah yaitu kesiapsiagaan bencana. Aspek pemahaman guru tentang program PRB yang telah mencapai respons $100 \%$ adalah:

1. Melaksanakan drill penyelamatan diri siswa diintegrasikan ke dalam pembelajaran tematik terpadu.

2. Meningkatkan kesadaran siswa dalam penyelamatan diri ketika terjadi bencana gempa melalui Yel-yel.

3. Meningkatkan pemahaman siswa tentang kesiapsiagaan bencana melalui tugas pembuatan kliping.

4. Merancang RPP tematik terintegrasi PRB.

Pemerintah telah menetapkan Kurikulum 2013 untuk diterapkan pada semua jenjang sekolah termasuk sekolah dasar (SD). Kemendikbud (2013:80) menjelaskan tujuan dari kurikulum 2013, yaitu untuk mempersiapkan insan Indonesia supaya memiliki kemampuan hidup sebagai pribadi dan warga negara yang beriman, produktif, kreatif, inovatif dan afektif serta mampu berkontribusi pada kehidupan bermasyarakat, berbangsa, bernegara dan peradaban dunia. Dalam kurikulum 2013 ini siswa dituntut untuk berpikir kritis, dapat melihat mana yang baik dan tidak baik serta dapat mengambil keputusan yang dapat memajukan hidup mereka dan hidup orang lain.

Sedangkan aspek pemahaman guru tentang program PRB berbasis ICT yang hanya mencapai respons $60 \%$ adalah melaksanakan latihan penyelamatan diri secara incidental dan memfasilitasi siswa dengan informasi PRB secara on-line(www.wartabencana.com). Kondisi tersebut lebih dikarenakan keterbatasan jaringan on-line di sekolah mitra.

Upaya tim untuk meningkatkan pemahaman siswa tentang kondisi tanah di daerah tempat tinggalnya menggunakan penyelidikan menggunakan "LKS Lezatnya Gempa" berbasis inkuiri. Tujuan penyelidikan tersebut adalah menemukan perbedaan antara tanah kuning padat dan tanah rawa atau gambut sudah berhasil meningkatkan pemahaman. Peningkatan pemahaman tersebut sesuai dengan pernyataan Winarni (2012: 30) bahwa model inkuiri dapat dimulai dengan memberikan pertanyaan dan cara bagaimana siswa menjawab pertanyaan tersebut Sikap siswa tentang program PRB sebagai bagian dari hasil belajar menunjukkan peningkatan. Hasil belajar adalah kemampuan yang diperoleh individu setelah proses belajar berlangsung, yang dapat memberikan perubahan tingkah laku meliputi pengetahuan, pemahaman, sikap dan keterampilan. Menurut Winarni (2012:138), hasil belajar adalah kemampuan-kemampuan yang dimiliki siswa setelah ia menerima pengalaman belajarnya. Artinya, hasil belajar merupakan pencapaian seorang siswa yang telah melakukan pembelajaran sehingga membuat siswa yang sebelumnya tidak mengerti menjadi mengerti. Ranah sikap (attitude) berkaitan dengan sikap dan nilai yang mencakup watak, perilaku seperti perasaan, minat, sikap, dan emosi. Ranah sikap (attitude) terdiri dari 
lima aspek yaitu: (1) menerima (accepting); (2) menanggapi (responding); (3) menilai (valuing); (4) mengelola (organizing/internalizing); dan (5) menghayati (characterizing/ actualing).

\section{KESIMPULAN DAN SARAN}

\section{Kesimpulan}

Kesimpulan kegiatan ini yaitu:

1. Telah tersusun lima buah RPP Pembelajaran Tematik terintegrasi program PRB sesuai dengan ketentuan dari Kurikulum 2013 dan berbasis ICT; dan

2. Persentase jumlah siswa yang mencapai kategori sangat baik dalam hal pemahaman dan sikap siswa tentang kesiapsiagaan bencana atau program PRB di sekolah mitra mengalami peningkatan.

\section{Saran}

Saran yang dapat diberikan melalui kegiatan ini, adalah:

1. Bagi sekolah mitra agar menyebarluaskan pengalaman saat menjadi mitra pendidikan kesiapsiagaan bencana ini kepada sekolah lainnya melalui Kelompok Kerja Guru;

2. Bagi guru pada sekolah mitra agar menyebarluaskan adanya sumber belajar tentang pendidikan kesiapsiagaan bencana yang dikemas dalam www.wartabencana.com;

3. Bagi jajaran Dikbud agar menindaklanjuti program ini secara lebih luas mengingat RPP produk IbM ini sangat relevan dengan implementasi Kurikulum 2013.

\section{DAFTAR PUSTAKA}

Kemendikbud, 2014, Peraturan Pemerintah No. 14 Tahun 2014 tentang Kurikulum 2013 Sekolah Dasar/Madrasah Ibtidayah.

Kemendikbud, 2013, Materi Pelatihan Guru Implementasi Kurikulum 2013, Kemendikbud, Jakarta.

Kompas, 14 Januari 2005, Pendidikan Layanan Khusus untuk Daerah-Daerah Bencana. 2013, Materi Pelatihan Guru Implementasi Kurikulum 2013, Kemendikbud, Jakarta.

Kompas. 15 September 2007. Pendidikan Kesiapsiagaan: Perlu Strategi.

Sri Dadi, Endang Widi, W, dan Karjiyati, 2012, Pengembangan Kurikulum Program Pengurangan Risiko Bencana secara Terintegrasi ke Dalam Mata Pelajaran di SDN 01 Kota Bengkulu, Laporan Penelitian Pembinaan, Bengkulu.

Wachidi, dkk., 2010, Pilot Project Sekolah Siaga Bencana di Provinsi Bengkulu, Lembaga Penelitian Unib: Laporan Penelitian Program Safer Community Disaster Risk Reduction (SCDRR) dan didukung UNDP.

Winarni, Endang Widi, 2012, Inovasi dalam Pembelajaran IPA, FKIP UNIB Press, Bengkulu.

Winarni, Endang W, Sri Dadi dan Feri Noperman, 2011, Diseminasi Model Pembelajaran 
Tematik Menggunakan Kebun Sekolah sebagai Alternatif Pendidikan Kesiapsiagaan Bencana di Sekolah Dasar, Lembaga Penelitian Unib: Laporan Penelitian Hibah Bersaing DP2M, Tahun Ketiga.

Winarni, Endang, W, Sri Dadi, dan Herman Lusa, 2010, Pengaruh Model Pembelajaran Tematik Kesiapsiagan Bencana terhadap Peningkatan Pemahaman Konsep, Kesadaran terhadap Bencana dan Motivasi belajar Siswa SD di Bengkulu, Lembaga Penelitian Unib: Laporan Penelitian Hibah Bersaing DP2M, Tahun Kedua.

Winarni, Endang, W, Sri Dadi, dan Abdul Muktadir, 2009, Pengembangan Model Pembelajaran Tematik menggunakan Kebun Sekolah sebagai Alternatif Pendidikan Kesiapsiagaan Bencana di Sekolah Dasar, Lembaga Penelitian Unib: Laporan Penelitian Hibah Bersaing DP2M, Tahun Pertama. 